\title{
A multiplex liquid-chip assay based on Luminex xMAP technology for simultaneous detection of six common respiratory viruses
}

\author{
Yong Yan ${ }^{1, *}$, Jian-Yong Luo ${ }^{1, *}$, Yin Chen ${ }^{2, *}$, Heng-Hui Wang ${ }^{1}$, Guo-Ying Zhu ${ }^{1}$, Pei- \\ Yan $\mathrm{He}^{1}$, Jin-Lei Guo ${ }^{1}$, Yong-Liang Lei ${ }^{3}$ and Zhong-Wen Chen ${ }^{1}$ \\ ${ }^{1}$ Jiaxing Key Laboratory of Pathogenic Microbiology, Jiaxing Municipal Center for Disease Control and Prevention, Jiaxing \\ 314050, China \\ ${ }^{2}$ Institute of Microbiology, Zhejiang Provincial Center for Disease Control and Prevention, Hangzhou 310051, China \\ ${ }^{3}$ Lishui Municipal Center for Disease Control and Prevention, Lishui 323000, China \\ *These authors contributed equally to this work \\ Correspondence to: Zhong-Wen Chen, email: heton74@hotmail.com
}

Keywords: Luminex, XMAP, respiratory virus, real-time RT-PCR, multiplex detection

Received: December 30, 2016 Accepted: June 02, 2017 Published: June 17, 2017

Copyright: Yan et al. This is an open-access article distributed under the terms of the Creative Commons Attribution License 3.0 (CC BY 3.0), which permits unrestricted use, distribution, and reproduction in any medium, provided the original author and source are credited.

\section{ABSTRACT}

We utilized one-step multiplex reverse transcription-PCR (RT-PCR) and Luminex XMAP technology to develop a respiratory multiplex liquid-chip assay ( $r$ MLA) for simultaneous detection of 6 common respiratory viruses, including influenza virus type A (FluA) and type B (FluB), para-influenza virus type 3 (PIV-3), respiratory syncytial virus (RSV), human metapneumovirus (MPV) and a threatening virus to China, Middle East Respiratory Syndrome coronavirus (MERS-CoV). Performance of rMLA was evaluated by comparing with real-time RT-PCR. Detection data from clinical specimens showed that the rMLA had diagnostic sensitivities of $97.10 \%$ for FluA, $\mathbf{9 4 . 5 9 \%}$ for FluB, $\mathbf{9 8 . 6 8} \%$ for PIV-3, $\mathbf{9 4 . 8 7 \%}$ for RSV and $\mathbf{9 5 . 9 2} \%$ for MPV (No Data for MERS-CoV due to the lack of positive specimens). Data of analytical sensitivities showed that the detection limits of the rMLA assay were 5-25 viral RNA copies per $\mu \mathrm{l}$ for FluA, FluB, PIV-3 and MERS-CoV, approximate to the real-time RT-PCR assay; while the values were 8 and 22 copies/ $\mu$ l for MPV and RSV, lower than the real-time RT-PCR(78 and 114 copies/ $\mu$ l respectively). The results indicated that the rMLA is a sensitive, specific detection tool and comparable to real-time RT-PCR, especially suitable for high-throughput detection of respiratory specimens.

\section{INTRODUCTION}

Human respiratory tract infection, mostly caused by respiratory viruses, gives rise to a considerable socioeconomic burden in medical care and social productivity due to the significant morbidity [1-5]. Unfortunately, respiratory viruses are various and clinical symptoms are very similar, so that it is almost impossible to distinguish them clinically [6]. Therefore, a rapid, sensitive, specific and multi-target assay for detecting major and common respiratory viruses is desirable. In addition, rapid and accurate diagnosis is important for adopting early antiviral treatment, preventing nosocomial spread, decreasing stay duration and reducing patient management costs [7-9].
Traditionally, respiratory viral infections have been diagnosed by cell culture, rapid antigen/antibody test, or direct fluorescent assay $[10,11]$. However, they are time-consuming, unable to give an early diagnosis. In many studies molecular diagnostic assays have been demonstrated to have superior sensitivity to conventional assays and are now being accepted as the new gold standard [12-15]. In particular, real-time PCR/RT-PCR shows significant superiorities due to its higher sensitivity and shorter turnaround time [16-19]. But, the limited multiplexing capacity of real-time PCR disables it to detect more targets and more clinical specimens in one assay simultaneously $[12,20]$. The flexible multi-analyte profiling (xMAP) technology developed by Luminex 
Corporation, integrates flow cytometry, encoding microspheres, lasers and digital signal processing, and offers a molecular diagnostic platform for simultaneous, high-throughput and multiplex detection of up to 100 targets in protein or nucleic acid study. Now it has been approved by US FDA for clinical diagnosis [22] and is being used in various applications [20-25]. Several assays or kits based on xMAP technology have been developed for the nucleic acid detection of respiratory viruses [11, 20, 26-28], but they still need to be improved or exploited for the new emerging respiratory viruses, such as influenza $\mathrm{A}(\mathrm{H} 1 \mathrm{~N} 1$ pandemic 2009) virus, avian influenza A(H7N9 2013) virus, Middle East Respiratory Syndrome coronavirus (MERS-CoV), etc.

In this study, one-step multiplex reverse transcription-PCR(RT-PCR) and Luminex xMAP technology were utilized to develop a respiratory multiplex LiquiChip assay (rMLA) for the detection of 6 common respiratory viruses in Jiaxing, including influenza virus type A (FluA) and B (FluB), parainfluenza virus type 3 (PIV-3), respiratory syncytial virus (RSV) and human metapneumovirus (MPV), as well as a potentially threatening virus, MERS-CoV [29]. MERS$\mathrm{CoV}$ was included into targets of the rMLA, considering the outbreak of MERS in South Korea in 2015 [30, 31] and the particular geographic location of Jiaxing, a north city of Zhejiang Province and near to Shanghai and Korea. The performance of rMLA was evaluated by comparing it to relevant real-time RT-PCR with clinical specimens from respiratory tract infection patients and synthetical standards from viral gene sequences.

\section{RESULTS}

\section{Analysis of analytical performance}

The analytical sensitivities of the Luminex-based rMLA and multiplex real-time RT-PCR assay developed in this study were assessed by testing in duplicate 10 -fold serial dilutions of positive standards ranging from $10^{6}$ to $10^{1}$ copies/ $\mu \mathrm{l}$ of viral RNA transcripts for each target. The standard curves were drawn by the $\log _{10}$ values of standard concentrations versus the MFI values for rMLA (Figure 1A) and the $C_{\mathrm{T}}$ values for real-time RT-PCR (Figure 1B). By calculating from the curves at the pre-set cutoff value mentioned in MATERIALS AND METHODS, the detection limits of the two assays were determined to be $7,10,6,22$, 8,11 and $9,12,8,114,78,15$ copies per $\mu$ for FluA, FluB, PIV-3, RSV, MPV, and MERS-CoV, respectively.

The analytical performance of the two assays was also assessed by testing positive controls and clinical specimens. As shown in Figure 2, both assays were able to detect all target viruses and no cross signals were observed. In order to further examine the performance of rMLA assay for mixed infection or co-infection specimens, two mixtures prepared randomly with positive controls, i.e. PC-Mix1 and PC-Mix2, containing three targets respectively, were tested in this study and each target was detected successfully with no interference signals from the others. The results showed that the rMLA had satisfying analytical specificities and multiplex detection capacity for target viruses.

\section{Analysis of diagnostic performance}

The new-developed rMLA and two-panel multiplex real-time RT-PCR were assessed for their diagnostic performance in practical application through detecting clinical specimens. The diagnostic sensitivities and specificities of both for each viral target were determined using the results of laboratory diagnosis by in-house monoplex real-time RT-PCR as the comparator with software SPSS version 19.0 (Table 1). No data were available for MERS-CoV due to the lack of positive specimens. Results showed that the rMLA assay has good diagnostic sensitivities for FluA $(97.10 \%, n=293)$, FluB $(94.59 \%, n=157)$, PIV3 $(98.68 \%, n=133)$, RSV $(94.87 \%, n=74)$ and MPV $(95.92 \%, n=82)$, approximate to the multiplex real-time RT-PCR. In order to observe the diagnostic consistency between the two new-developed assays, both of detection data were re-analyzed by SPSS (Table 2). The Kappa values of five targets were more than 0.919 , suggesting a great consistency in their diagnostic performance. In addition, we found that all of false-negative specimens for RSV and MPV by rMLA had real-time PCR results of $C_{\mathrm{T}}$ over 38 . The $C_{\mathrm{T}}$ values of specimens with false-negative results ranged from 38.1 to 39.6 for RSV; and the values ranged from 38.3 to 39.8 for MPV. This suggested that the detection limits of rMLA for the two targets were lower than the multiplex real-time RT-PCR.

\section{Analysis of assay reproducibility}

In order to learn the performances of assays in the hands of others, the reproducibilities of developed rMLA and multiplex real-time RT-PCR assay were assessed. Same positive specimen for each target was tested in duplicate by three different technicians for ten times in three months to monitor the inter-assay variation. That for MERS-CoV due to the lack of positive specimen was replaced by a positive control with $10^{5}$ copies/ $\mu$ of RNA transcripts. The coefficient of variations (CVs, $n=10)$ of inter-assay were fluA 9.68\%, fluB 7.22\%, PIV3 13.48\%, RSV $8.81 \%$, MPV $10.32 \%$, MERS-CoV $9.17 \%$ for the rMLA, and fluA $9.03 \%$, fluB $8.16 \%$, PIV3 $12.12 \%$, RSV $8.54 \%$, MPV $9.62 \%$, MERS-CoV $8.29 \%$ for the realtime RT-PCR. The CVs of intra-assay obtained by testing ten positive specimens in duplicate for each target(using positive controls for MERS-CoV), were fluA $6.21 \%$, fluB $5.20 \%$, PIV3 $8.76 \%$, RSV $7.28 \%$, MPV $7.68 \%$, MERSCoV $6.41 \%$ for the rMLA, and fluA $7.04 \%$, fluB $7.52 \%$, 
PIV3 9.83\%, RSV 8.53\%, MPV 8.40\%, MERS-CoV $6.06 \%$ for the real-time RT-PCR. The results showed that the reproducibilities of two assays are comparable in practical application.

\section{Analysis of cost effectiveness}

Reagent cost and turnaround time of our developed rMLA and two-panel multiplex real-time RT-PCR were listed in Table 3. The real-time RT-PCR with the advantages of simultaneous target amplification and analysis, required $\sim 2 \mathrm{~h}(130 \mathrm{~min})$ to test one plate if two panels of the assay were availably setup in one 96well plate (the number of tested specimens is less than 46 , due to at least 2 wells needed for positive and blank control). While, the rMLA took at least $\sim 3 \mathrm{~h}(190 \mathrm{~min})$ to test one plate $(<=93$ specimens, 3 wells for positive PC-Mix1, PC-Mix2 and blank control) due to the subsequent hybridization and Luminex analysis after target amplification.
A workload of two plates (i.e. $2 * 96$ reactions) were used to compare the multi-target and throughput capability of two assays . The two-panel multiplex realtime RT-PCR needed four times to spend up to $\sim 7 \mathrm{~h}$ (440 $\mathrm{min}$ ) and $\$ 2,472$ (\$12.88/reaction) for all reactions when only one real-time PCR instrument was available; While, the Luminex-based rMLA need at most $6 \mathrm{~h}$ (350 $\mathrm{min}$ ) and $\$ 2,580$ (\$13.44/reaction). If an ordinary/ standard thermocycler was simultaneously available for amplification, being feasible in most labs, the overall turnaround time of the rMLA assay could be shorten to $\sim 4.5 \mathrm{~h}$ (260 $\mathrm{min})$. If more specimens needed to be tested within an 8-h clinical shift, the rMLA can still be setup by one technician to run another plate with another ordinary thermocycler. This is an easier and more costeffective alternative to purchase and run several real-time instruments in parallel. Additionally, above cost analysis was based on the reagent prices in China, which are obviously higher than those in US, especially the Luminex beads. It was reported that the total reagent cost for a
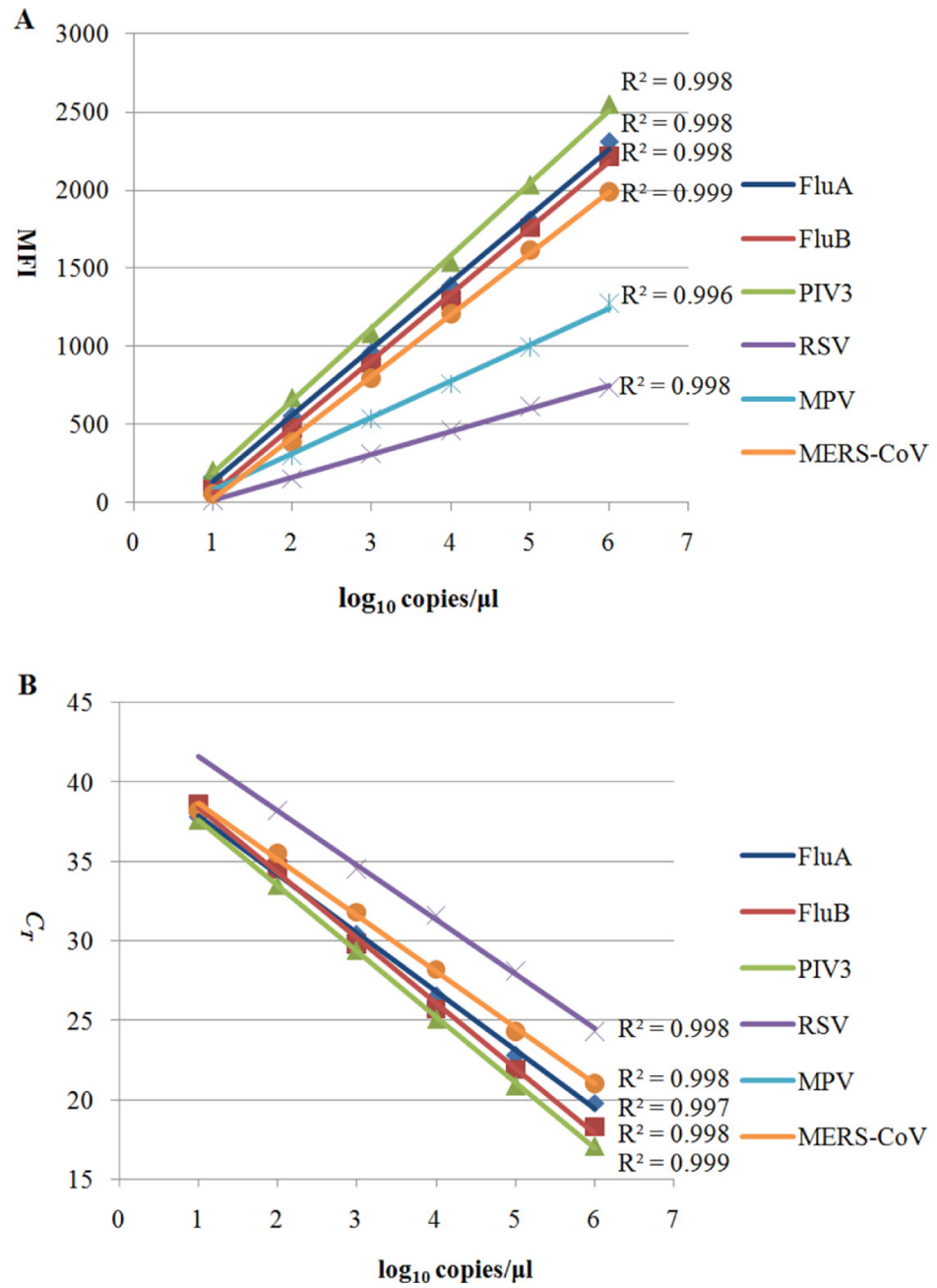

Figure 1: Comparison of the analytical sensitivity of the two assays developed in this study. Viral in vitro RNA transcripts of six targets were used as standards. The concentrations of each target in standard curves were expressed in $\log _{10} \operatorname{copies} / \mu 1$ versus the median fluorescence intensity(MFI) values of Luminex-based rMLA assay $(\mathbf{A})$ or the threshold cycle $\left(C_{T}\right)$ values of real-time RT-PCR assay $(\mathbf{B})$. 
Table 1: Diagnostic sensitivity and specificity of the Luminex-based rMLA and the real-time RT-PCR assay ${ }^{\mathrm{a}}$

\begin{tabular}{|c|c|c|c|c|c|c|c|c|c|}
\hline \multirow{2}{*}{ Target } & \multirow{2}{*}{$\begin{array}{c}\text { Lab } \\
\text { Diagnosis }\end{array}$} & \multicolumn{4}{|c|}{ rMLA assay } & \multicolumn{4}{|c|}{ Real-time RT-PCR assay } \\
\hline & & + & - & Sensitivity (\%) & Specificity (\%) & + & - & Sensitivity(\%) & Specificity $(\%)$ \\
\hline \multirow[t]{2}{*}{ FluA } & + & 234 & 7 & 97.10 & 96.15 & 232 & 9 & 96.27 & 96.15 \\
\hline & - & 2 & 50 & & & 2 & 50 & & \\
\hline \multirow[t]{2}{*}{ FluB } & + & 105 & 6 & 94.59 & 100.00 & 104 & 7 & 93.69 & 100.00 \\
\hline & - & 0 & 46 & & & 0 & 46 & & \\
\hline \multirow[t]{2}{*}{ PIV3 } & + & 75 & 1 & 98.68 & 96.49 & 73 & 3 & 96.05 & 98.25 \\
\hline & - & 2 & 55 & & & 1 & 56 & & \\
\hline \multirow[t]{2}{*}{ RSV } & + & 37 & 2 & 94.87 & 97.14 & 35 & 4 & 89.74 & 94.29 \\
\hline & - & 1 & 34 & & & 2 & 33 & & \\
\hline \multirow[t]{2}{*}{ MPV } & + & 47 & 2 & 95.92 & 100.00 & 45 & 4 & 91.84 & 96.97 \\
\hline & - & 0 & 33 & & & 1 & 32 & & \\
\hline
\end{tabular}

aPlus mark, Positive; minus mark, Negative. ${ }^{b}$ Laboratory diagnostic methods used previously, adopting in-house monoplex real-time RT-PCR. ${ }^{~}$ Representing the two-panel multiplex real-time RT-PCR assay developed in this study.

Luminex xMAP analysis was $\$ 3.90$ per test, and $\$ 9.42$ per test for a three-panel duplex real-time RT-PCR to detect six targets [20].

\section{DISCUSSION}

In this study, we developed two multiplex assays: a Luminex-based rMLA and a two-panel triplex realtime RT-PCR for six respiratory viruses, five of which were common respiratory viruses in Jiaxing, i.e. FluA,
FluB, PIV-3, RSV, and MPV. While the MERS-CoV is a potentially threatening virus to Jiaxing. This is the first report to describe a Luminex-based laboratory-developed assay designed specifically in order to include MERS-CoV as one of targets. Several commercial Luminex-based kits for respiratory viruses are available now, such as $\mathrm{xTAG}^{\mathrm{TM}}$ respiratory virus panel (RVP) and $\mathrm{xTAG}^{\mathrm{TM}}$ RVP Fast (Luminex Corp.), MultiCode ${ }^{\circledR}$-PLx (EraGen Biosciences), ResPlex II Kit (QIAGEN) [26, 32, 33], however, they either involve too complicated steps, or include too many

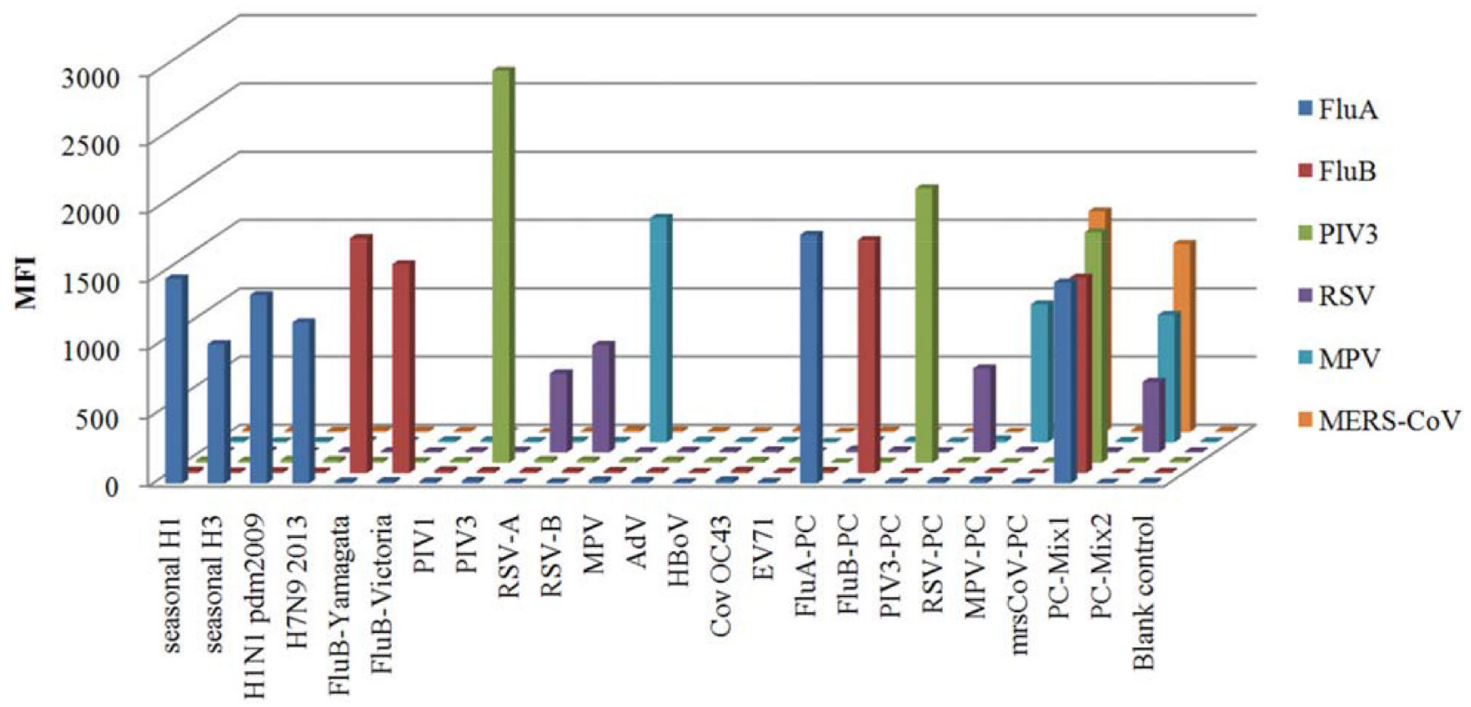

Samples or controls

Figure 2: Analytical specificity of the Luminex-based rMLA assay. The specificity analysis was carried out with viral RNA from positive samples of influenza A virus seasonal H1N1 and H3N2, H1N1 pdm 2009, H7N9 2013, influenza B virus Yamagata and Victoria lineage, PIV1, PIV3, RSV-A, RSV-B, MPV, AdV, HBov, Cov OC43, EV71, and positive controls(PC) of $10^{5}$ viral copies/ $\mu 1$ for each target. Two random mixtures of positive controls, PC-Mix1 and PC-Mix2, were used to analyze multi-target detection capacity for co-infection samples briefly. Free-Rnase water was used as a blank control . Biotin-labelled RT-PCR products of samples or controls $(x$ axis) were identified by bead-coupled capture probes ( $z$ axis) and showed by the MFI values ( $y$ axis). 
Table 2: Consistency in diagnostic performence of the rMLA and real-time RT-PCR assay ${ }^{\mathrm{a}}$

\begin{tabular}{|c|c|c|c|c|c|c|}
\hline \multirow{2}{*}{ Target } & \multirow{2}{*}{ Real-time RT-PCR ${ }^{b}$} & \multicolumn{2}{|c|}{ rMLA } & \multirow{2}{*}{$\begin{array}{c}\text { Accordance } \\
\text { Rate }(\%)\end{array}$} & \multirow{2}{*}{ Kappa } & \multirow{2}{*}{ Approx. Sig. } \\
\hline & & + & - & & & \\
\hline \multirow[t]{2}{*}{ FluA } & + & 234 & 0 & 99.32 & 0.979 & 0.000 \\
\hline & - & 2 & 57 & & & \\
\hline \multirow[t]{2}{*}{ FluB } & + & 104 & 0 & 99.36 & 0.986 & 0.000 \\
\hline & - & 1 & 52 & & & \\
\hline \multirow[t]{2}{*}{ PIV3 } & + & 74 & 1 & 97.74 & 0.954 & 0.000 \\
\hline & - & 2 & 56 & & & \\
\hline \multirow[t]{2}{*}{ RSV } & + & 36 & 1 & 95.95 & 0.919 & 0.000 \\
\hline & - & 2 & 35 & & & \\
\hline \multirow[t]{2}{*}{ MPV } & + & 45 & 1 & 96.34 & 0.925 & 0.000 \\
\hline & - & 2 & 34 & & & \\
\hline
\end{tabular}

aPlus mark, Positive; minus mark, Negative. ${ }^{b}$ Representing the two-panel multiplex real-time RT-PCR assay developed in this study.

Table 3: Cost-effectiveness comparison of the rMLA and real-time RT-PCR assay

\begin{tabular}{|c|c|c|c|c|}
\hline Assays & Time/plate & Time (2 plates) & Cost/reaction ${ }^{a}$ & $\operatorname{Cost}(2 \text { plates })^{a}$ \\
\hline \multicolumn{5}{|l|}{ Real-time RT-PCR ${ }^{b}$} \\
\hline RNA extraction & $40 \mathrm{~min}$ & $80 \mathrm{~min}$ & $\$ 6.25$ & $\$ 1,200.00$ \\
\hline First RT-PCR Panel $1(25 \mu \mathrm{l})$ and analysis & $90 \mathrm{~min}$ & $90 \mathrm{~min}$ & $\$ 3.31$ & $\$ 318.00$ \\
\hline TaKaRa One Step RT-PCR reagents & & \multicolumn{3}{|c|}{$\$ 0.78$} \\
\hline Primers (forward and reverse, 3 targets) & & \multicolumn{3}{|c|}{$\$ 0.19$} \\
\hline TaqMan fluorescent probes (3 targets) & & \multicolumn{3}{|c|}{$\$ 2.34$} \\
\hline First RT-PCR Panel $2(25 \mu \mathrm{l})$ and analysis & & $90 \mathrm{~min}$ & $\$ 3.31$ & $\$ 318.00$ \\
\hline Second RT-PCR Panel 1 ( $25 \mu \mathrm{l})$ and analysis & & $90 \mathrm{~min}$ & & $\$ 318.00$ \\
\hline Second RT-PCR Panel $2(25 \mu \mathrm{l})$ and analysis & & $90 \mathrm{~min}$ & & $\$ 318.00$ \\
\hline Total & $130 \mathrm{~min}$ & $440 \mathrm{~min}$ & $\$ 12.88$ & $\$ 2,472.00$ \\
\hline \multicolumn{5}{|l|}{ rMLA } \\
\hline RNA extraction & $40 \mathrm{~min}$ & $80 \mathrm{~min}$ & $\$ 6.25$ & $\$ 1,200.00$ \\
\hline RT-PCR (25 $\mu$ l volume) & $90 \mathrm{~min}$ & $90 \mathrm{~min}$ & $\$ 1.72$ & $\$ 330.00$ \\
\hline TaKaRa One Step RT-PCR reagents & & \multicolumn{3}{|c|}{$\$ 0.78$} \\
\hline Primers (biotin-forward and reverse, 6 targets) & & & \multicolumn{2}{|l|}{$\$ 0.94$} \\
\hline Luminex analysis (hybridization \&.Reading data) & $60 \mathrm{~min}$ & $90 \mathrm{~min}$ & & \\
\hline $\begin{array}{l}\text { Capture probes (6 targets) \&. hybridizatio } \\
\text { reagents }\end{array}$ & & & $\$ 5.47$ & $\$ 1,050.00$ \\
\hline Total & $190 \mathrm{~min}$ & $260 \mathrm{~min}$ & $\$ 13.44$ & $\$ 2,580.00$ \\
\hline
\end{tabular}

${ }^{a}$ Based on the purchase prices in China in 2015 and the condition of an ordinary lab with only one standard PCR, a real-time PCR and a Luminex instrument. These do not include costs for common lab reagents, disposables, instruments and labor. ${ }^{b}$ Representing the two-panel multiplex real-time RT-PCR assay developed in this study.

targets, or do not have targets we need, e.g. MERS-CoV. Importantly, they are too expensive for routine detection in clinical laboratory.
Over the past ten years, 'in-house' real-time PCR/ RT-PCR assays have been used by our lab for the diagnosis and surveillance of viral respiratory tract illnesses and 
showed the good characteristics of rapid and simplicity due to the advantage of simultaneous amplification and analysis, without post-amplification manipulation $[34,35]$. However, the primers and probes provided by provincial CDC and state CDC were designed specifically for individual target, so these 'in-house' assays for lab diagnosis were mostly monoplex. Although multiplex real-time RT-PCR was also used in work, the limited multiplexing and throughput capacity became its obvious shortcomings due to the limited fluorescent channels in a real-time instrument and the adverse interactions between primers and probes in one reaction [20,35]. So, a multiplex real-time RT-PCR assay for more targets has to be divided into two or more panels, such as our developed real-time RT-PCR assay with two panels for six respiratory viruses in this study. This makes the limited throughput capacity more detrimental and tight. In epidemic period, the assay requires more plates, more technicians and more turnaround time, otherwise the lab needs to buy more machines in parallel to run a large number of samples within a limited work shift.

In view of the facts, the rMLA assay was developed on a Luminex multiplex platform (Bio-Plex 200) for multitarget and high-throughput detection. The platform allows for detecting more targets simultaneously and performing continuous analysis for plate queue. The bottleneck of multiplex PCR in Luminex xMAP technology for nucleotide analysis, though still exists, is not so intractable due to the post-amplification analysis. This decreases the possibility of interferences from capture probes in that they are added in the hybridization step. And the primer/ probe design for a Luminex assay becomes easier because the criterion of probe and the size of amplicon are not as strict as a real-time PCR. However, the product should be less than $300 \mathrm{bp}$ to assure the amplification efficiency and analytical sensitivity [36]. In this study, the same primers and probes (slightly modified) shared by the rMLA and the real-time RT-PCR ensured not only the amplification efficiency and sensitivity of the rMLA assay, but also ensured the comparability of the two assays. Actually we had explored the possibility of transplanting a real-time PCR assay to a Luminex xMAP analysis. Our results indicated that this is feasible, of course, and may need slight modifications specially for the Luminex analysis.

In this study, our developed rMLA assay and multiplex real-time PCR assay had diagnostic sensitivities of more than $90 \%$ for the five targets (No Data for MERS$\mathrm{CoV}$ due to no positive specimens) and no cross reaction was found. No obvious difference was also found between the both, and in fact the great consistency of the diagnostic performance presented in the detection of clinical specimens(accordance rates $>95 \%$, Kappa values $>0.9$ for all targets). Some reports had the similar result [36, 37], but there were also reports that Luminex XMAP analysis for some target was more or less sensitive than real-time PCR [20,37]. This mostly depended on the primer design and reaction optimization of the assay according to our experiences. Sensitivity analysis showed that the detection limits of the rMLA for FluA, FluB, PIV-3 and MERS-CoV were 5-25 copies/ $\mu 1$ of viral RNA, approximate to the real-time RT-PCR, and those of the rMLA for MPV and RSV were 8 and 22 copies $/ \mu$ l, lower than the real-time RT$\operatorname{PCR}(78$ and 114 copies/ $\mu 1$ respectively). But, the detection limits of the rMLA for the six targets could be up to 6,9 , $5,15,6$ and 10 copies $/ \mu$, if the cutoffs for rMLA were set at three times the blank control recommended by ACS Commitee on Environmental Improvement [38]. Above results indicated that the overall performance of rMLA was comparable to the real-time RT-PCR, suggesting that the analytical sensitivities of rMLA for two targets, RSV and MPV, may be higher than the real-time RT-PCR, despite not confirmed by our statistical data in diagnosis.

Technically, Luminex xMAP analysis has higher sensitivity and specificity than real-time PCR since the liquid-phase hybridization after amplification can decrease the background interference and two-fluorescence detection can increase the specificity [28, 36]. Through the study, we believe that we can make the rMLA assay better with some improvements. Its sensitivity and specificity can be improved by asymmetric multiplex PCR, adopting a protocol of differential cycle conditions based on temperature differential primer design $[20,39,40]$. The extra exonuclease I can be added to eliminate the residual primers before hybridization [11, 36]. So, the overall turnaround time of the assay may increase a little (less than 30 minutes). In addition, the reaction volume of amplification will be adjusted to $10 \mu \mathrm{l}$ (containing $2.5 \mu \mathrm{l}$ of viral RNA template), and all product will be used for hybridization so that the amplification, hybridization and analysis of the rMLA can be all handled in only one 96-well plate. This will make the assay more convenient and economic, and greatly reduce the probability of carryover contamination between pre- and post-amplification steps. However, these could be our next work. Though we have not done so yet, a large number of data based on the established research program had been obtained and were in line with our study objectives.

In conclusion, the new-developed real-time RTPCR for 6 common respiratory viruses is suitable for the emergency detection of a small number of specimens due to the advantage of rapid and simplicity. While, our developed Luminex-based rMLA has great sensitivity and specificity comparable to the real-time RT-PCR, and a higher throughput capability to run large numbers of specimens simultaneously, significantly reducing the cost. Furthermore, due to the Luminex platform's flexibility, the rMLA can be expanded to include more respiratory pathogen targets, to meet local seasonal or emerging changes of respiratory infectious diseases. 


\section{MATERIALS AND METHODS}

\section{Ethics statement}

Informed consent was obtained from all participants before this study was conducted. The study and all procedures were approved by Jiaxing Municipal Center for Disease Control and Prevention (Jiaxing CDC), and carried out in accordance with biosafety and ethical standards of the institutional and national research committee and the relevant laws and regulations of People's Republic of China.

\section{Clinical specimens and positive controls}

A total of 739 respiratory specimens were mainly from specimens submitted to Jiaxing CDC by hospitals in Jiaxing from 2013 to 2015, and partially from Zhejiang Provincial Center for Disease Control and Prevention (Zhejiang CDC). These specimens were mostly nasopharyngeal swabs, a small number of tracheal aspirations and bronchoalveolar lavages, and were collected in viral transport medium and stored at $-80^{\circ} \mathrm{C}$. All had been tested by in-house real-time RT-PCR (monoplex) according to the relevant diagnostic criteria of respiratory tract infection. The used primers and probes were provided by Zhejiang CDC and Chinese CDC, or synthesized in accordance with the sequences from both.

Additionally, all positive controls of target viruses (Table 4) were prepared by synthesizing target DNA and transcribing it into RNA. Target DNAs were synthesized by Shanghai Sangon Biotech Co., Ltd. (Sangon) and RNA transcription was performed with the MEGAscript ${ }^{\mathbb{}}$ RNAi Kit (Catalog\#AM1626, Ambion, USA). After purification and concentration using MagMAX ${ }^{\mathrm{TM}}$-96 Viral RNA Isolation Kit (Catalog\#AM1836, Ambion, USA) on KingFisher Flex system (Thermo Fisher Scientific Inc., USA), the in vitro RNA transcripts were quantified with NanoDrop $^{\text {TM }} 2000$ microspectrophotometer (Thermo Fisher Scientific Inc., USA) and adjusted to $10^{7}$ copies per $\mu 1$ using EASY Dilution for Real-Time PCR (Cat\#D9160A, TaKaRa, China,Dalian) as original quantification standards in this study. The dilutions containing $10^{5}$ copies $/ \mu$ of viral RNA transcripts were used as positive controls and 10 -fold serial dilutions were used to determine analytical sensitivity of the following assays. All of these were stored at $-80^{\circ} \mathrm{C}$ until analysis.

\section{Viral RNA extraction}

All specimens were vortexed and resuspended before viral RNA extraction. $75 \mu \mathrm{l}$ specimens were used to extract viral RNA by using the MagMax ${ }^{\mathrm{TM}}-96$ Viral RNA Isolation Kit on the KingFisher Flex system according to the manufacturer's recommendation. $75 \mu \mathrm{l}$ viral RNA extracts were collected and stored at $-80^{\circ} \mathrm{C}$ before use.
In addition, FluA positive control (FluA-PC), containing $10^{5}$ copies/ $\mu$ l of FluA RNA transcripts, was added into extraction procedure in order to monitor RNA extraction efficiency by comparing the concentrations before and after the extraction.

\section{Primers and probes}

The primers, TaqMan probes and capture probes used in this study were listed in Table 5. Those aiming at FluA, PIV3, RSV, MPV were improved or redesigned by our lab, so that the targets of the assays included new emerging or more viruses, such as FluA target including influenza A virus subtype 2009 pdm H1N1 and H7N9 2013, RSV target including RSV group A and B. Primers and TaqMan probes for FluB and MERS-CoV were not changed, respectively from the sequences recommended by Chinese National Influenza Center (CNIC) and World Health Organization (WHO). All of the forward primers, reverse primers, TaqMan probes and modified forward primers(-F+) with 5 '-biotin were synthesized by Sangon, and the capture probes(-P+) coupled to fluorescentencoding microspheres (beads) through $5^{\prime}$ amino-C12 linker, only used for Luminex-based rMLA assay, were designed by our lab and synthesized by Shanghai Tellgen Life Science Co., Ltd. (Tellgen).

\section{Real-time RT-PCR assay}

A one step multiplex real-time RT-PCR assay was developed by our lab using TaKaRa One Step PrimeScript ${ }^{\mathrm{TM}}$ RT-PCR Kit(Cat\# RR064A), and divided into Panel 1 for FluA, FluB, PIV3 and Panel 2 for RSV, MPV and MERS-CoV, due to only 5 channels available for detection on the CFX96 ${ }^{\text {TM }}$ Touch Real-time PCR System(Bio-Rad Laboratories Inc., USA). The final 25 $\mu \mathrm{l}$ mixture for each reaction contained $5 \mu$ viral RNA extract and optimized concentrations of the primers (-F and $-\mathrm{R}$ ) and TaqMan probes (Table 2). Both panels of the real-time RT-PCR assay were performed in condition of $42^{\circ} \mathrm{C}$ for $30 \mathrm{~min}, 95^{\circ} \mathrm{C}$ for $1 \mathrm{~min}$, and 45 cycles of $95^{\circ} \mathrm{C}$ for $15 \mathrm{sec}$ and $55^{\circ} \mathrm{C}$ for $45 \mathrm{sec}$. Qualitative result of the assay was determined as follows: the threshold cycle value $\left(C_{T}\right)$ $<35$, positive; no amplification or $C_{T}>38$ (considered as an invalid amplification), negative; $C_{T}$ between 35-38, reserved, if still range between 35-38 after redoing, considered it as positive. The average $C_{T}$ value was determined for each standard dilution or sample in two replicates, and the detection limit of the assay for each target was estimated from the standard curve at a cutoff point of $C_{T}$ value (The value was set to 38 in this study).

\section{Luminex-based rMLA assay}

A multiplex RT-PCR for 6 targets, including FluA, FluB, PIV3, RSV, MPV and MERS-CoV, was performed 
Table 4: Positive controls used in this study

\begin{tabular}{|c|c|c|}
\hline Positive control & Sequence $\left(5^{\prime}-3^{\prime}\right)$ & Reference seq ID and position ${ }^{a}$ \\
\hline FluA-PC & $\begin{array}{l}\text { GAAAGAACACAGATCTTGAGGCTCTCA } \\
\text { TGGAATGGCTAAAGACAAGACCA } \\
\text { ATCTTGTCACCTCTGACTAAGGGA } \\
\text { ATTTTAGGATTTGTGTTCACGCTCA } \\
\text { CCGTGCCCAGTGAGCGAGGACTGC } \\
\text { AGCGTAGACGATTTGTCCAAAATGC } \\
\text { CCTAAATGGGAATGGGGACCCGAACAA } \\
\text { CATGGATAGAGCAGTTAAACTATAC }\end{array}$ & $\begin{array}{l}\text { KP317439:101-300 } \\
\text { Influenza A virus (A/Delhi/053/2011(H1N1)), } \\
\text { matrix protein } 1 \text { (M1) gene, complete cds. }\end{array}$ \\
\hline FluB-PC & $\begin{array}{l}\text { TGGAGGATGAAGAAGATGGCCATCGGAT } \\
\text { CCTCAACTCACTCTTCGAGCGTCTTAATG } \\
\text { AAGGACATTCAAAGCCAATTCGAGCAGC } \\
\text { TGAAACTGCGGTGGGAGTCTTATCCCAAT } \\
\text { TTGGTCAAGAGCACCGATTATCAC } \\
\text { CAGAAGAGGGAGACAA }\end{array}$ & $\begin{array}{l}\text { KT223814:707-860 } \\
\text { Influenza B virus (B/California/NHRC_M1023/ } \\
\text { 2014) segment } 8 \text { nuclear export protein (NEP) } \\
\text { gene, partial cds and nonstructural protein } 1 \\
\text { (NS1) gene, complete cds. }\end{array}$ \\
\hline PIV3-PC & $\begin{array}{l}\text { CACAGGAAGCATTGTATCATCTGT } \\
\text { CATATTGGACTCACAAAAATCGA } \\
\text { GAGTCAACCCAGTCATAACTTACT } \\
\text { CAACAGCAACCGAAAGGGTA } \\
\text { AACGAGCTGGCTATCCGAAACAAAACACT }\end{array}$ & $\begin{array}{l}\text { KJ672618:8181-8300 } \\
\text { Human parainfluenza virus } 3 \text { strain HPIV3/ } \\
\text { Homo sapiens/PER/CFI1849/2012, complete } \\
\text { genome. }\end{array}$ \\
\hline RSV-PC & $\begin{array}{l}\text { TGGGGCAAATATGGAAACATACG } \\
\text { TGAACAAACTTCACGAGGGCTC } \\
\text { CACATACACAGCTGCTGTTCA } \\
\text { ATACAATGTCCTAGAAAAAGA } \\
\text { CGATGATCCTGCATCACTTACA } \\
\text { ATATGGGTGCCCATGTTCCAA }\end{array}$ & $\begin{array}{l}\text { KP317953:3251-3380 } \\
\text { Human respiratory syncytial virus isolate } \\
\text { Kilifi_11862_29_RSVA_2011, complete } \\
\text { genome. }\end{array}$ \\
\hline MPV-PC & $\begin{array}{l}\text { ATGTCTCTTCAAGGGATTCAC } \\
\text { CTAAGTGATCTGTCATATAAA } \\
\text { CATGCCATATTAAAAGAGTCT } \\
\text { CAATACACAATAAAAAGAGAT } \\
\text { GTAGGCACCACAACTGCAGTG } \\
\text { ACACCTTCATCATTGCAACAAG } \\
\text { AAATAACACTT }\end{array}$ & $\begin{array}{l}\text { KJ627435:1-138 } \\
\text { Human metapneumovirus strain HMPV/Homo } \\
\text { sapiens/PER/FLE0425/2009/A, complete } \\
\text { genome. }\end{array}$ \\
\hline mrsCoV-PC & $\begin{array}{l}\text { CCACTGTTTTCGTGCCTG } \\
\text { CAACGCGCGATTCAGTTCCTCTT } \\
\text { CACATAATCGCCCCGAGCTCGCT } \\
\text { TATCGTTTAAGCAGCTCTGCGCTA } \\
\text { CTATGGGTCCCGTGTAGAGGCTAA } \\
\text { TCCATTAGTCTCTCTTTG }\end{array}$ & $\begin{array}{l}\text { KP209307:27441-27570 } \\
\text { Middle East respiratory syndrome coronavirus } \\
\text { strain Abu Dhabi_UAE_18_2014, complete } \\
\text { genome. }\end{array}$ \\
\hline
\end{tabular}

${ }^{a}$ Reference seq ID is accession No. of the sequence in NCBI GenBank.

with the same TaKaRa One Step PrimeScript ${ }^{\mathrm{TM}}$ RT-PCR Kit. The $25 \mu \mathrm{l}$ reaction mixture contained $5 \mu \mathrm{l}$ viral RNA extract and optimized concentrations of biotin-modified forward primers (-F+) and reverse primers (-R) (Table 5), using same sequences as those of real-time RT-PCR assay described above. After the amplification, $3 \mu$ biotinlabeled PCR product of each reaction was added into 22 $\mu \mathrm{l}$ working bead mixture prepared temporarily (containing 3,000 beads coupled with capture probe of each target) and followed by hybridization of $95^{\circ} \mathrm{C}$ for $5 \mathrm{~min}$ and $50^{\circ} \mathrm{C}$ for $20 \mathrm{~min}$ on the CFX96 ${ }^{\mathrm{TM}}$ Touch Real-time PCR System. Then, $75 \mu \mathrm{l}$ of working reporter solution $(3 \mu \mathrm{g} /$ $\mathrm{ml}$ streptavidin-phycoerythrin) was added into the mixture followed by incubation at $50^{\circ} \mathrm{C}$ for $5 \mathrm{~min}$. The original bead solution of each target, original SA-PE reporter solution and $1 \times$ tetramethyl ammonium chloride (TMAC) hybridization buffer for dilution were all provided by Tellgen. In the end, $100 \mu$ final volume of the mixture was analyzed on a Bio-Plex 200 system (Bio-Rad Laboratories Inc., USA) at $48^{\circ} \mathrm{C}$. The median fluorescence intensity (MFI) of at least 50 beads was reported for each bead set. The average MFI value was determined for each standard dilution or sample in duplicate. The cutoff value for a positive result was set at five times the background MFI 
Table 5: PCR primers, Taqman probes and capture probes used in this study

\begin{tabular}{|c|c|c|c|c|c|}
\hline Target & Primer or Probe $^{\mathrm{a}}$ & Sequence $\left(5^{\prime}-3^{\prime}\right)^{b}$ & $\begin{array}{l}\text { Reference seq and } \\
\text { position }^{c}\end{array}$ & Modification & $\begin{array}{l}\text { Reaction } \\
\text { Concentration }(\mu \mathrm{M})\end{array}$ \\
\hline \multirow{4}{*}{$\begin{array}{l}\text { FluA Matrix } \\
\text { protein(M) } \\
\text { gene }\end{array}$} & FluA-F/FluA-F+ & GACCRATCYTGTCACCTCTGAC & KP317439:146-167 & FluA-F+:5'-Biotin & 0.5 \\
\hline & FluA-R & GGGCATTYTGGACAAAKCGTCTACG & KP317439:226-250 & & 0.5 \\
\hline & FluA-P & TGCAGTCCTCGCTCACTGGGCACG & KP317439:201-224(-) & 5'-FAM,3'-BHQ1 & 0.25 \\
\hline & FluA-P+ & AGTCCTCGCTCACTGGGCAC & KP317439:204-223(-) & 5'-linker-bead(\#34) & 0.25 \\
\hline \multirow{4}{*}{$\begin{array}{l}\text { FluB Nuclear } \\
\text { Export Protein } \\
\text { (NEP) gene }\end{array}$} & FluB-F/FluB-F+ & TCCTCAACTCACTCTTCGAGCG & KT223814:734-755 & FluB-F+:5'-Biotin & 0.5 \\
\hline & FluB-R & CGGTGCTCTTGACCAAATTGG & KT223814:816-836 & & 0.5 \\
\hline & FluB-P & CCAATTCGAGCAGCTGAAACTGCGGTG & KT223814:778-804 & 5'-HEX,3'-BHQ1 & 0.25 \\
\hline & FluB-P+ & CCAATTCGAGCAGCTGAAACTG & KT223814:778-799 & 5'-linker-bead $(\# 42)$ & 0.25 \\
\hline \multirow{4}{*}{$\begin{array}{l}\text { PIV3 } \\
\text { Nucleoprotein(N) } \\
\text { gene }\end{array}$} & PIV3-F/PIV3-F+ & GGAAGCATTGTRTCATCTGTC & KJ672618:8185-8205 & PIV3-F+:5'-Biotin & 0.6 \\
\hline & PIV3-R & TCGGATRGCCAGCTCGT & KJ672618:8273-8289(-) & & 0.6 \\
\hline & PIV3-p & ACCCAGTMATAACTTACTCAACAGC & KJ672618:8234-8258 & $5^{\prime}-\mathrm{ROX}, 3^{\prime}-\mathrm{BHQ} 1$ & 0.3 \\
\hline & PIV3-p+ & ACCCAGTMATAACTTACTCAACA & KJ672618:8234-8256 & $5^{\prime}$-linker-bead $(\# 21)$ & 0.3 \\
\hline \multirow{4}{*}{$\begin{array}{l}\text { RSV Matrix } \\
\text { protein(M) } \\
\text { gene }\end{array}$} & RSV-F/RSV-F+ & GCAAATATGGAAACATACGTGAACA & KP317953:3255-3279 & RSV-F+:5'-Biotin & 0.5 \\
\hline & RSV-R & GCACCCATATTGTWAGTGATGCA & KP317953:3347-3369(-) & & 0.5 \\
\hline & RSV-P & CTTCACGAGGGCTCCACATACACAGC & KP317953:3282-3307 & 5'-FAM,3'-BHQ1 & 0.25 \\
\hline & RSV-P+ & AGGGCTCCACATACACAGC & КР317953:3289-3307 & 5'-linker-bead( $(\# 26)$ & 0.25 \\
\hline \multirow{4}{*}{$\begin{array}{l}\text { MPV } \\
\text { Nucleoprotein(N) } \\
\text { gene }\end{array}$} & MPV-F/MPV-F+ & TCTCTTCAAGGGATTCACCT & KJ627435:4-23 & MPV-F+:5'-Biotin & 0.48 \\
\hline & MPV-R & GTTATTTCTTGTTGCAATGATGA & KJ627435:112-134(-) & & 0.48 \\
\hline & MPV-P & CATGCYATATTAAAAGAGTCTCARTAC & KJ627435:43-69 & 5'-HEX,3'-BHQ1 & 0.24 \\
\hline & MPV-P+ & CATGCYATATTAAAAGAGTCTCA & KJ627435:43-69 & 5'-linker-bead $(\# 48)$ & 0.24 \\
\hline \multirow{4}{*}{$\begin{array}{l}\text { MERS-CoV } \\
\text { upstream of E } \\
\text { protein(upE) } \\
\text { region }\end{array}$} & $\mathrm{mrsCoV}-\mathrm{F} / \mathrm{mrsCoV}-\mathrm{F}+$ & GCAACGCGCGATTCAGTT & KP209307:27458-27475 & mrsCoV-F+:5'-Biotin & 0.5 \\
\hline & mrsCoV-R & GCCTCTACACGGGACCCATA & KP209307:27530-27549(-) & & 0.5 \\
\hline & mrsCoV-P & СTCTTCACATAATCGCCCCGAGCTCG & KP209307:27477-27502 & 5'-ROX,3'-BHQ1 & 0.25 \\
\hline & mrsCoV-P+ & CTCTTCACATAATCGCCCCGAGC & KP209307:27477-27497 & 5'-linker-bead(\#62) & 0.25 \\
\hline
\end{tabular}

${ }^{\mathrm{a}} \mathrm{F}, \mathrm{R}, \mathrm{P}$ respectively represents forward primer, reverse primer and TaqMan probe used for real-time RT-PCR. Modified forward primer(F+) and capture probe $(\mathrm{P}+)$, with plus mark, only used for Luminex-based rMLA. ${ }^{\mathrm{b}}$ Degenerate bases: R,A or G; Y,C or T; K, T or G; M, A or C; W, A or T. ${ }^{\mathrm{C}}$ Reference seq ID is accession number of the sequence in NCBI GenBank. Sequence with minus mark is antisense.

value of the blank control and the detection limit of the assay for each target was calculated from the standard curve at the cutoff of MFI value.

\section{ACKNOWLEDGMENTS}

The authors are grateful to Dr. Yu-Wen Luo of Bio-Rad Laboratories Inc. (Shanghai) and Dr. Yu-Qiong Zhuo of Tellgen Life Science Co., Ltd.(Shanghai) for the technique support of Luminex XMAP analysis. The authors also thank the First Affiliated Hospital of Jiaxing University for providing clinical samples and relevant data.

\section{CONFLICTS OF INTEREST} interest.

All authors declare that they have no conflicts of

\section{FUNDING}

This study was financially supported by the Science and Technology Project of Zhejiang Province (Grant No. 2014C33247). The funder had no role in study design, data collection and analysis, decision to publish, or preparation of the manuscript.

\section{REFERENCES}

1. Alonso WJ, Laranjeira BJ, Pereira SA, Florencio CM, Moreno EC, Miller MA, Giglio R, Schuck-Paim C, Moura FE. Comparative dynamics, morbidity and mortality burden of pediatric viral respiratory infections in an equatorial city. Pediatr Infect Dis J. 2012; 31:e9-14.

2. Karaivanova GM. Viral respiratory infections and their role as public health problem in tropical countries (review). Afr J Med Med Sci. 1995; 24:1-7.

3. Bertino JS. Cost burden of viral respiratory infections: issues for formulary decision makers. Am J Med. 2002 (Suppl 6A); 112:42S-49S.

4. Molinari NA, Ortega-Sanchez IR, Messonnier ML, Thompson WW, Wortley PM, Weintraub E, Bridges CB. The annual impact of seasonal influenza in the US: measuring disease burden and costs. Vaccine. 2007; 25:5086-96.

5. Thompson WW, Comanor L, Shay DK. Epidemiology of seasonal influenza: use of surveillance data and statistical 
models to estimate the burden of disease. J Infect Dis. 2006 (Suppl 2); 194:S82-91.

6. Brunstein J, Thomas E. Direct screening of clinical specimens for multiple respiratory pathogens using the Genaco Respiratory Panels 1 and 2. Diagn Mol Pathol. 2006; 15:169-73.

7. Henrickson KJ. Cost-effective use of rapid diagnostic techniques in the treatment and prevention of viral respiratory infections. Pediatr Ann. 2005; 34:24-31.

8. Lee N, Chan PK, Hui DS, Rainer TH, Wong E, Choi KW, Lui GC, Wong BC, Wong RY, Lam WY, Chu IM, Lai RW, Cockram CS, Sung JJ. Viral loads and duration of viral shedding in adult patients hospitalized with influenza. J Infect Dis. 2009; 200:492-500.

9. Novak-Weekley SM, Marlowe EM, Poulter M, Dwyer D, Speers D, Rawlinson W, Baleriola C, Robinson CC. Evaluation of the Cepheid Xpert Flu Assay for rapid identification and differentiation of influenza A, influenza A 2009 H1N1, and influenza B viruses. J Clin Microbiol. 2012; 50:1704-10.

10. Mahony JB, Petrich A, Smieja M. Molecular diagnosis of respiratory virus infections. Crit Rev Clin Lab Sci. 2011; 48:217-49.

11. Mahony J, Chong S, Merante F, Yaghoubian S, Sinha T, Lisle C, Janeczko R. Development of a respiratory virus panel test for detection of twenty human respiratory viruses by use of multiplex PCR and a fluid microbead-based assay. J Clin Microbiol. 2007; 45:2965-70.

12. Létant SE, Ortiz JI, Bentley Tammero LF, Birch JM, Derlet RW, Cohen S, Manning D, McBride MT. Multiplexed reverse transcriptase PCR assay for identification of viral respiratory pathogens at the point of care. J Clin Microbiol. 2007; 45:3498-505.

13. Kuypers J, Campbell AP, Cent A, Corey L, Boeckh M. Comparison of conventional and molecular detection of respiratory viruses in hematopoietic cell transplant recipients. Transpl Infect Dis. 2009; 11:298-303.

14. Templeton KE, Scheltinga SA, Beersma MF, Kroes AC, Claas EC. Rapid and sensitive method using multiplex real-time PCR for diagnosis of infections by influenza a and influenza B viruses, respiratory syncytial virus, and parainfluenza viruses 1, 2, 3, and 4. J Clin Microbiol. 2004; 42:1564-69.

15. Weinberg GA, Erdman DD, Edwards KM, Hall CB, Walker FJ, Griffin MR, Schwartz B, and New Vaccine Surveillance Network Study Group. Superiority of reverse-transcription polymerase chain reaction to conventional viral culture in the diagnosis of acute respiratory tract infections in children. J Infect Dis. 2004; 189:706-10.

16. Harnden A, Brueggemann A, Shepperd S, White J, Hayward AC, Zambon M, Crook D, Mant D. Near patient testing for influenza in children in primary care: comparison with laboratory test. BMJ. 2003; 326:480.

17. Kok J, Blyth CC, Foo H, Patterson J, Taylor J, McPhie K, Ratnamohan VM, Iredell JR, Dwyer DE. Comparison of a rapid antigen test with nucleic acid testing during cocirculation of pandemic influenza A/H1N1 2009 and seasonal influenza A/H3N2. J Clin Microbiol. 2010; 48:290-91.

18. Kuypers J, Wright N, Ferrenberg J, Huang ML, Cent A, Corey L, Morrow R. Comparison of real-time PCR assays with fluorescent-antibody assays for diagnosis of respiratory virus infections in children. J Clin Microbiol. 2006; 44:2382-88.

19. Szewczuk E, Thapa K, Anninos T, McPhie K, Higgins G, Dwyer DE, Stanley KK, Iredell JR. Rapid semi-automated quantitative multiplex tandem PCR (MT-PCR) assays for the differential diagnosis of influenza-like illness. BMC Infect Dis. 2010; 10:113.

20. Munro SB, Kuypers J, Jerome KR. Comparison of a multiplex real-time PCR assay with a multiplex Luminex assay for influenza virus detection. J Clin Microbiol. 2013; 51:1124-29.

21. Anderson S, Wakeley P, Wibberley G, Webster K, Sawyer J. Development and evaluation of a Luminex multiplex serology assay to detect antibodies to bovine herpes virus 1 , parainfluenza 3 virus, bovine viral diarrhoea virus, and bovine respiratory syncytial virus, with comparison to existing ELISA detection methods. J Immunol Methods. 2011; 366:79-88.

22. Dunbar SA. Applications of Luminex xMAP technology for rapid, high-throughput multiplexed nucleic acid detection. Clin Chim Acta. 2006; 363:71-82.

23. Glushakova LG, Bradley A, Bradley KM, Alto BW, Hoshika S, Hutter D, Sharma N, Yang Z, Kim MJ, Benner SA. High-throughput multiplexed xMAP Luminex array panel for detection of twenty two medically important mosquito-borne arboviruses based on innovations in synthetic biology. J Virol Methods. 2015; 214:60-74.

24. Liu J, Kibiki G, Maro V, Maro A, Kumburu H, Swai N, Taniuchi M, Gratz J, Toney D, Kang G, Houpt E. Multiplex reverse transcription PCR Luminex assay for detection and quantitation of viral agents of gastroenteritis. J Clin Virol. 2011; 50:308-13.

25. Silbereisen A, Tamborrini M, Wittwer M, Schürch N, Pluschke G. Development of a bead-based Luminex assay using lipopolysaccharide specific monoclonal antibodies to detect biological threats from Brucella species. BMC Microbiol. 2015; 15:198.

26. Gadsby NJ, Hardie A, Claas EC, Templeton KE. Comparison of the Luminex Respiratory Virus Panel fast assay with in-house real-time PCR for respiratory viral infection diagnosis. J Clin Microbiol. 2010; 48:2213-16.

27. Li H, McCormac MA, Estes RW, Sefers SE, Dare RK, Chappell JD, Erdman DD, Wright PF, Tang YW. Simultaneous detection and high-throughput identification of a panel of RNA viruses causing respiratory tract infections. J Clin Microbiol. 2007; 45:2105-09.

28. Washington C, Metzgar D, Hazbón MH, Binn L, Lyons A, Coward C, Kuschner R. Multiplexed Luminex xMAP assay 
for detection and identification of five adenovirus serotypes associated with epidemics of respiratory disease in adults. J Clin Microbiol. 2010; 48:2217-22.

29. Su S, Wong G, Liu Y, Gao GF, Li S, Bi Y. MERS in South Korea and China: a potential outbreak threat? Lancet. 2015; 385:2349-50.

30. Lee SI. Costly Lessons From the 2015 Middle East Respiratory Syndrome Coronavirus Outbreak in Korea. J Prev Med Public Health. 2015; 48:274-76.

31. Park HY, Lee EJ, Ryu YW, Kim Y, Kim H, Lee H, Yi SJ. Epidemiological investigation of MERS-CoV spread in a single hospital in South Korea, May to June 2015. Euro Surveill. 2015; 20:1-6.

32. Balada-Llasat JM, LaRue H, Kelly C, Rigali L, Pancholi P. Evaluation of commercial ResPlex II v2.0, MultiCodePLx, and xTAG respiratory viral panels for the diagnosis of respiratory viral infections in adults. J Clin Virol. 2011; 50:42-45.

33. Pabbaraju K, Wong S, Tokaryk KL, Fonseca K, Drews SJ. Comparison of the Luminex xTAG respiratory viral panel with XTAG respiratory viral panel fast for diagnosis of respiratory virus infections. J Clin Microbiol. 2011; 49:1738-44.

34. Mijatovic-Rustempasic S, Tam KI, Kerin TK, Lewis JM, Gautam R, Quaye O, Gentsch JR, Bowen MD. Sensitive and specific quantitative detection of rotavirus $\mathrm{A}$ by onestep real-time reverse transcription-PCR assay without antecedent double-stranded-RNA denaturation. J Clin Microbiol. 2013; 51:3047-54.

35. Yan Y, Wang HH, Gao L, Ji JM, Ge ZJ, Zhu XQ, He PY, Chen ZW. A one-step multiplex real-time RT-PCR assay for rapid and simultaneous detection of human norovirus genogroup I, II and IV. J Virol Methods. 2013; 189:277-82.

36. Xiaoyan L, Jinying C, Mei K, Xu S, Ming Z, Liru G. Development of high-throughput liquid chips for respiratory virus detection. Clin Lab. 2014; 60:347-61.

37. Hamza IA, Jurzik L, Wilhelm M. Development of a Luminex assay for the simultaneous detection of human enteric viruses in sewage and river water. J Virol Methods. 2014; 204:65-72.

38. MacDougall D, Crummett WB, ACS Commitee on Environmental Improvement. Guidelines for data acquisition and data quality evaluation in environmental chemistry. Anal Chem. 1980; 52:2242-49.

39. Lodes MJ, Suciu D, Wilmoth JL, Ross M, Munro S, Dix K, Bernards K, Stöver AG, Quintana M, Iihoshi N, Lyon WJ, Danley DL, McShea A. Identification of upper respiratory tract pathogens using electrochemical detection on an oligonucleotide microarray. PLoS One. 2007; 2:e924.

40. Sanchez JA, Pierce KE, Rice JE, Wangh LJ. Linear-afterthe-exponential (LATE)-PCR: an advanced method of asymmetric PCR and its uses in quantitative real-time analysis. Proc Natl Acad Sci USA. 2004; 101:1933-38. 